\title{
FORMAÇÃO E FIXAÇÃO DE PESQUISADORES NA REGIÃO NORTE DO BRASIL: o Projeto Norte de Pós-Graduação e Pesquisa/Capes
}

Manoel Santana Cardoso

Curso: Mestrado em Sociologia

Data de defesa da dissertação: 29 de novembro de 2004 Orientador: Prof. Dr. Carlos Benedito Martins

\section{Resumo}

A presente dissertação tem como temática o desequilíbrio existente entre a base técnico-científica que se verifica na Região Norte do Brasil em relação às demais regiões. Ainda, as consequiências deste desequilíbrio para o sistema de pós-graduação das IES amazônicas, tendo em vista as dificuldades para o processo de formação e fixação de docentes pesquisadores na região.

O objetivo é promover uma análise crítica das ações do Projeto Norte de Pós-Graduação e Pesquisa (PNOPG), a partir da evolução dos índices e indicadores utilizados pela Fundação Coordenação de Aperfeiçoamento de Pessoal de Nível Superior (Capes), para avaliar a expansão do sistema de pós-graduação no país. A intenção é medir a eficácia deste instrumento de política pública, o PNOPG, na redução dos índices de desequilíbrio da base técnico-científica.

Concluímos que as ações do PNOPG foram de fato responsáveis pela expansão do sistema de C\&T na Amazônia, no entanto, algumas limitações impediram um avanço maior deste sistema. Essas razões estão ligadas à não participação de alguns setores no processo e à ausência de uma ação conjunta com outros 
510 Resumos das teses e dissertações defendidas no PPG-SOL/UnB

atores interessados no encaminhamento das ações referentes ao Projeto Norte de Pós-Graduação e Pesquisa.

Palavras-chave: educação superior, pós-graduação, desequilíbrio regional, Região Norte. 